\title{
Bakery work, atopy and the incidence of self-reported hay fever and rhinitis
}

\author{
J. Brisman*,+, B. Järvholm*,*
}

Bakery work, atopy and the incidence of self-reported hay fever and rhinitis. J. Brisman, B. Järvholm. C) ERS Journals Ltd 1999.

ABSTRACT: The aims of this study were to estimate the risk to bakers of developing hay fever and rhinitis, to assess the modifying effect of atopy and to estimate the occurrence of job change due to nasal symptoms.

A retrospective cohort study was performed among bakers trained in Swedish trade schools from 1961 to $1989(n=2,923)$. School control subjects $(n=1,258)$ comprised students in other programmes in the trade schools and population controls $(n=1,258)$ were randomly selected from the general population. A questionnaire on hay fever, rhinitis, the year of onset of these diseases, change of work due to nasal symptoms and work history was mailed to all participants. The atopic state of the responders was assessed by questions on allergic diseases in childhood and among next of kin. Incidence rates for hay fever and other rhinitis were calculated.

The relative risk (RR) for hay fever when working as a baker compared with all control subjects combined was increased in males $(R R=1.9,95 \%$ confidence interval (CI) 1.2-2.9). The RR for rhinitis in male bakers compared with combined control subjects was $2.8(95 \%$ CI 2.3-3.4) and for female bakers 2.0 (1.6-2.7). Of the bakers, $6.1 \%$ had changed job due to nasal symptoms, significantly more than the controls. A history of respiratory atopy increased the incidence rates of hay fever and rhinitis, with a synergistic effect between atopy and bakery work in males.

In conclusion, Swedish bakers, mainly working in the 1970 s and 1980s, had an approximately doubled risk of developing rhinitis. Male bakers also had an increased risk for hay fever. There was a synergistic effect of bakery work and atopy such as a family history of hay fever. Bakers also changed job due to nasal symptoms more often than control subjects.

Eur Respir J 1999; 13: 502-507.

Cases of work-related rhinitic symptoms in bakers exposed to flour dust are well known in the literature [1]. Cross-sectional studies of bakers have shown prevalences of rhinitis ranging from 18 to $29 \%$ [2-5]. Baker's rhinitis can be caused by immunoglobulin E (IgE)-mediated allergic reactions to flour or additives, but often no sensitization to occupational allergens is demonstrated $[6,7]$. Thus, flour dust and additives are likely to cause allergic as well as nonallergic occupational rhinitis. The influence of atopy on the risk of baker's rhinitis is not clear.

In the Finnish Register of Occupational Diseases, exposure to flour dust comprised $24 \%$ of the reported cases of occupational rhinitis and was, after animal dander, the second most common aetiological agent of rhinitis [8]. The age-standardized rate ratio, as an estimate of the relative risk, was 22 (95\% confidence interval (CI) 17-29) compared with the working Finnish population.

Rhinitic symptoms per se impair quality of life [9]. In addition, baker's rhinitis may develop into baker's asthma. In fact, most cases of baker's asthma are reported to be preceded by rhinitis [2].

The objectives of the present investigation were to estimate the incidence of hay fever and other rhinitic symptoms in bakers and control subjects. The modifying effect of atopy was also studied, as well as changes of job due to nasal symptoms.
*Institute of Internal Medicine, Section of Occupational Medicine, and ${ }^{+}$Dept of Respiratory Medicine and Allergology, Göteborg University, Göteborg, Sweden. ${ }^{2}$ Dept of Occupational and Environmental Medicine, Umea University, Umea, Sweden.

Correspondence: J. Brisman, Dept of Occupational Medicine, S: t Sigfridsgatan 85 B, S-412 66 Göteborg, Sweden, Fax: 46 31409728

Keywords: Atopy

bakers

epidemiology

hay fever

incidence

rhinitis

Received: December 191997

Accepted after revision November 81998

Supported by the Swedish Work Environment Fund, the Vardal Foundation and the Swedish Asthma and Allergy Association

Methods

Study design and subjects

The study was of retrospective cohort design using a postal questionnaire. The subjects comprised all people born from 1943 to 1972 who had graduated from bakery classes in Swedish trade schools from 1961 to 1989 according to school records. These people usually followed a bakery programme for 2 yrs, usually beginning at the age of 16 yrs. In this way, 2,986 people, trained to become bakers, were identified.

Two control groups were used in the study. One group (school controls) comprised people also born from 1943 to 1972, who went to the same trade schools, during the same period as the bakers, but following different programmes. They were mostly trained in other trades in the food-processing industry, such as butchers, cooks, brewery or dairy workers. For every 10 bakers, four controls from the same school and year were selected at random. The total number of school controls was 1,290.

Ninety-five bakers and school controls were not found in the population register in 1992 and were excluded from the study. Of these, 12 were dead, 14 had emigrated and three changed address at the time of the study. The registrar was not allowed to give the addresses of another three 
people and 63 people were not located in the register, probably because of changed social security numbers or emigration without notifying the authorities. After these exclusions 2,923 bakers and 1,258 school controls remained.

A second control group (population controls) was selected at random from the Swedish population register, stratified for sex and 10-yr birth-class, comprising 1,258 people.

The study was approved by the Committee of Ethics of Göteborg University and by the Data Inspectorate.

\section{Questionnaire}

A self-administered questionnaire was mailed to all participants in late 1992. The two questions about nasal symptoms were: "Do you have or have you had hay fever?" (Question (Q) 11A) and "Do you have or have you had other nasal symptoms than hay fever (a blocked or runny nose and/or attacks of sneezes without having a cold)?" (Q12A). An affirmative response to question 11A was followed by: "How old were you when the hay fever started?" (Q11B) and an affirmative answer to Q12A by: "How old were you when your other nasal symptoms started?" (Q12B). Hay fever was defined as a positive answer to question Q11A and rhinitis as a positive answer to Q12A. The question concerning change of work was: "Have you ever changed job due to hay fever or other nasal symptoms?" (Q20B).

There were two questions on history of respiratory atopy: "Have any of your parents or siblings suffered from asthma?" (Q21A), or "hay fever?" (Q21B) Questions on skin atopic history were: "Did you have childhood eczema?" (Q19) and: "Have any of your parents or siblings suffered from atopic eczema?" (Q21C).

The questionnaire also contained information on asthma, skin symptoms and occupational history. The results on the occurrence of asthma and hand eczema have been published elsewhere $[10,11]$.

A total of 5,439 questionnaires were sent out. The response rates after two reminders were: former baker students 2,226/2,923 (76.2\%), school controls 931/1,258 (74.0\%), and population controls 930/1,258 (73.9\%). In all three groups there were significantly more females among the responders than among the nonresponders. When controlling for sex, there was no difference in age between responders and nonresponders.

\section{Reliability}

A second, identical questionnaire was mailed to 200 randomly selected subjects who had answered the first questionnaire without any reminder. The second questionnaire was sent out 5 months after the first one. The response rate was $73 \%$. Agreement between discrete variables was estimated by the kappa coefficient [12]. The kappa coefficient of the question on hay fever (Q11A) was 0.84 and for rhinitis (Q12A) 0.66.

The reliability of the temporal aspect of the onset of hay fever (Q11B in the questionnaire) and rhinitis (Q12B) was also studied. Forty-two subjects reported hay fever in both questionnaires. Two of them did not answer Q11B on the second occasion. Fourteen subjects gave identical answers to Q11B and the answers of 10 subjects differed by $1 \mathrm{yr}$, of six subjects by 2 yrs, of five subjects by 3 yrs, of two subjects by 4 yrs, and in one subject each the difference was 5, 6 and 9 yrs.

Fifty-two subjects reported rhinitis on both occasions, 10 of whom did not answer Q12B on one of the occasions. Twelve subjects gave identical answers to Q12B on the two occasions and the answers of nine subjects differed by $1 \mathrm{yr}$, in eight subjects by $2 \mathrm{yrs}$, in two subjects by $3 \mathrm{yrs}$, in two subjects by 4 yrs, in three subjects by 5 yrs, in two subjects by $7 \mathrm{yrs}$, in one person each the difference was 6 , 9, 14 and 20 yrs.

\section{Data analysis}

Incidence rates were calculated by the number of new cases of hay fever and rhinitis per person-yrs under observation (1961-1992). The person-yrs in bakers and school controls were calculated from the year they left the trade school programme and through 1992 or until they developed hay fever or rhinitis. Population controls contributed person-yrs from $18 \mathrm{yrs}$ of age, i.e. the age at which most bakers left school, until 1992 or until hay fever or rhinitis started. If hay fever or rhinitis was reported before the age of 18 yrs or if the starting year was unknown, the subject was excluded from the incidence study of that nasal symptom. In bakers, the incidence rate was calculated separately for time working as a baker and for time in other occupations. Incidence rate ratios were calculated and are referred to as relative risks. Ninety-five per cent confidence intervals of the relative risk were calculated with the testbased method [13]. The p-values for prevalence ratios were calculated with the Chi-squared test. A multiple logistic regression analysis was performed with the Proc Logist module of the SAS software package (SAS Institute, Cary, $\mathrm{NC}$, USA) estimating the odds ratio for reporting rhinitis with onset at $18 \mathrm{yrs}$ of age or later. Independent variables were occupational history, sex, childhood eczema and a family history of hay fever or asthma. Only p-values $<0.05$ are indicated.

\section{Results}

Of the 2,226 former baker students answering the questionnaire, 1,644 (73.9\%) had worked as bakers after leaving school ("ever bakers"), while 558 (25.1\%) had never worked as bakers ("never bakers"), and 24 (1.0\%) did not report their working history. The mean age for males $(n=1,280)$ was 31 yrs and for females $(n=946) 27$ yrs.

The cumulative prevalence of hay fever was significantly lower in "ever bakers" than in the population controls (13.6 versus $17.1 \%$; table 1 ). The lifetime cumulative prevalence of rhinitis was significantly higher among "ever bakers" than in all control groups. The lowest prevalences of hay fever and rhinitis with onset at 15 yrs of age or earlier and of a family history of hay fever were found among "ever bakers". Six per cent of the "ever bakers" had changed job owing to nasal symptoms, significantly more than any of the control groups.

The incidence rate of hay fever was about 4 cases $\cdot 1,000$ person-yrs ${ }^{-1}$ when working as a baker, compared with 1.92.7 cases in male and 3.7-5.7 cases in female control subjects (table 2). 
Table 1. - Cumulative prevalences of self-reported hay fever and rhinitis, of a family history of hay fever and change of job due to rhinitis in bakers, school and population controls

\begin{tabular}{|c|c|c|c|c|}
\hline & \multicolumn{2}{|c|}{$\begin{array}{c}\text { Former bakery } \\
\text { students. Ever } \\
\text { worked as baker }\end{array}$} & \multirow{2}{*}{ 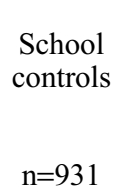 } & \multirow{2}{*}{$\begin{array}{l}\text { Population } \\
\text { controls } \\
\text { n=930 }\end{array}$} \\
\hline & $\begin{array}{c}\text { Yes } \\
\mathrm{n}=1,644\end{array}$ & $\begin{array}{c}\text { No } \\
\mathrm{n}=558\end{array}$ & & \\
\hline \multicolumn{5}{|l|}{ Prevalence $\%$} \\
\hline \multicolumn{5}{|l|}{ Lifetime } \\
\hline Hay fever & 13.6 & 13.9 & 16.3 & $17.1 *$ \\
\hline Rhinitis & 33.2 & $22.6 * * *$ & $27.5 * *$ & $28.0 * *$ \\
\hline \multicolumn{5}{|l|}{ Up to $15 \mathrm{yrs}$ of age } \\
\hline Hay fever & 7.5 & 8.8 & $10.5 * *$ & $10.7 * *$ \\
\hline Rhinitis & 5.4 & 6.4 & 7.3 & $9.4 * *$ \\
\hline $\begin{array}{l}\text { Family history of } \\
\text { hay fever }\end{array}$ & 16.3 & 17.0 & 19.3 & $21.0 * *$ \\
\hline $\begin{array}{c}\text { Changed job due to } \\
\text { nasal symptoms }\end{array}$ & 6.1 & $2.7 * *$ & $0.8^{* * *}$ & $1.6^{* * *}$ \\
\hline
\end{tabular}

All comparisons are made between those former bakery students who have ever worked as bakers and the respective comparison group. *: $\mathrm{p}<0.05 ; * *$ : $\mathrm{p}<0.01 ; * * *: \mathrm{p}<0.001 ;$ compared with former bakery students who had worked as a baker.

The incidence of rhinitis during work as a baker was about 30 cases 1,000 person-yrs ${ }^{-1}$ in both sexes, compared with about 10 cases 1,000 person-yrs ${ }^{-1}$ in male controls and approximately 15 cases 1,000 person-yrs ${ }^{-1}$ in female controls (table 2). The median time between reported onset of rhinitis during bakery work and answering the questionnaire was 5 yrs (95th percentile was 9 yrs).

The relative risk of hay fever in males was greater during work as a baker than in school and population control subjects (table 3 ), in contrast to females. For both sexes, the relative risk of rhinitis was significantly greater during work as a baker than in any comparison group (table 3 ). The estimated relative risks ranged 2.6-2.9 for males and 1.8-2.4 for females.

Subjects with a family history of hay fever had increased incidence rates of hay fever and rhinitis during bakery work than in other occupations and in the control groups (table 4).

There was an association between the occurrence of hay fever or rhinitis and asthma diagnosed by a physician. Prevalences of asthma among people with hay fever ranged $15-24 \%$, the lowest in "ever bakers" and the highest in

Table 2. - Incidence rates of hay fever and rhinitis from the age of 18 yrs onwards in former bakery students and controls

\begin{tabular}{lcccc}
\hline & \multicolumn{3}{c}{ Former bakery students } & \\
\cline { 2 - 3 } & $\begin{array}{c}\text { When working When in other } \\
\text { as baker }\end{array}$ & $\begin{array}{c}\text { School Population } \\
\text { occupations }\end{array}$ & controls & controls \\
\hline $\begin{array}{c}\text { Hay fever } \\
\text { Males }\end{array}$ & $4.4(30)$ & $2.7(25)$ & $1.9(13)$ & $2.3(16)$ \\
$\begin{array}{c}\text { Females } \\
\text { Rhinitis }\end{array}$ & $3.8(10)$ & $3.7(18)$ & $5.7(22)$ & $4.1(15)$ \\
Males & $29.4(179)$ & $10.1(87)$ & $11.1(73)$ & $10.1(68)$ \\
Females & $30.1(74)$ & $12.8(59)$ & $16.3(69)$ & $15.6(56)$ \\
\hline
\end{tabular}

Data are shown as number of cases 1,000 person-yrs ${ }^{-1}$ (number of incident cases).
Table 3. - Relative risk (RR) of hay fever and rhinitis in bakers, compared with bakers during time in other occupations, school and population controls

\begin{tabular}{|c|c|c|c|c|c|c|}
\hline & \multicolumn{6}{|c|}{ Comparison group } \\
\hline & \multicolumn{2}{|c|}{$\begin{array}{l}\text { Bakers when in } \\
\text { other occupation }\end{array}$} & \multicolumn{2}{|c|}{$\begin{array}{l}\text { School } \\
\text { control }\end{array}$} & \multicolumn{2}{|c|}{$\begin{array}{l}\text { Population } \\
\text { control }\end{array}$} \\
\hline & RR & $95 \% \mathrm{CI}$ & RR & $95 \% \mathrm{CI}$ & RR & $95 \% \mathrm{CI}$ \\
\hline \multicolumn{7}{|l|}{ Hay fever } \\
\hline Males & 1.6 & $0.94-2.7$ & 2.2 & $1.2-4.2$ & 1.9 & $1.1-3.5$ \\
\hline Females & 1.0 & $0.44-2.5$ & 0.67 & $0.32-1.4$ & 0.92 & $0.41-2.1$ \\
\hline \multicolumn{7}{|l|}{ Rhinitis } \\
\hline Males & 2.9 & $2.3-3.7$ & 2.6 & $2.0-3.4$ & 2.9 & $2.2-3.8$ \\
\hline Females & 2.4 & $1.6-3.1$ & 1.8 & $1.3-2.6$ & 1.9 & $1.4-2.7$ \\
\hline
\end{tabular}

CI: confidence interval.

population control subjects. The corresponding figures for people with rhinitis ranged $10-17 \%$, with the lowest prevalence in "never bakers" and the highest in population control subjects. The corresponding prevalences in people without hay fever or rhinitis ranged $3.0-4.3 \%$.

A family history of asthma increased the incidence of hay fever by a factor of 1.4-2.8; the incidence of rhinitis was not affected among males but was increased by a factor of about 1.5 in females (data not shown). Subjects with skin atopy (a report of own childhood eczema or a family history of atopic eczema) increased incidence rates of rhinitis, except for females in relation to a family history of eczema (table 5). Among bakers, the incidence rates of hay fever in both sexes and of rhinitis in females were highest during the first year of employment (table 6). In general, the incidence rates were higher in subjects $<26$ yrs of age (table 7).

Table 4. - Incidence rates of hay fever and rhinitis from the age of 18 yrs onwards according to a family history of hay fever

\begin{tabular}{|c|c|c|c|}
\hline Former b & ery students & & \\
\hline $\begin{array}{l}\text { When } \\
\text { working }\end{array}$ & $\begin{array}{l}\text { When in } \\
\text { other }\end{array}$ & $\begin{array}{c}\text { School } \\
\text { controls }\end{array}$ & $\begin{array}{c}\text { Population } \\
\text { controls }\end{array}$ \\
\hline
\end{tabular}

\begin{tabular}{lrrrr}
\hline Hay fever & & & & \\
Males & & & & \\
Family history & & & & \\
$\quad$ Yes & $18.8(12)$ & $9.5(7)$ & $10.1(8)$ & $10.1(8)$ \\
$\quad$ No & $2.5(14)$ & $1.9(14)$ & $0.9(5)$ & $1.4(8)$ \\
Females & & & & \\
Family history & & & & \\
$\quad$ Yes & $15.3(6)$ & $11.5(9)$ & $11.6(6)$ & $3.5(2)$ \\
$\quad$ No & $1.5(3)$ & $1.9(7)$ & $4.9(15)$ & $4.5(12)$ \\
Rhinitis & & & & \\
Male & & & & \\
Family history & & & & \\
$\quad$ Yes & $48.3(29)$ & $16.8(13)$ & $18.1(17)$ & $15.7(14)$ \\
$\quad$ No & $27.7(136)$ & $9.9(68)$ & $10.6(54)$ & $8.9(48)$ \\
Females & & & & \\
Family history & & & & \\
$\quad$ Yes & $44.7(17)$ & $24.6(19)$ & $24.6(12)$ & $22.3(13)$ \\
$\quad$ No & $26.1(49)$ & $10.8(37)$ & $15.6(45)$ & $14.8(39)$ \\
\hline
\end{tabular}

Date are shown as number of new cases 1,000 person-yrs ${ }^{-1}$ according to a family history of hay fever (number of incident cases). 
Table 5. - Incidence rates of rhinitis from the age of 18 yrs onwards according to childhood eczema or a family history of atopic eczema

\begin{tabular}{cccc}
\multicolumn{2}{c}{ Former bakery students } & & \\
\cline { 1 - 2 } $\begin{array}{c}\text { When } \\
\text { working } \\
\text { as baker }\end{array}$ & $\begin{array}{c}\text { When in } \\
\text { other } \\
\text { occupation }\end{array}$ & $\begin{array}{c}\text { School } \\
\text { controls }\end{array}$ & $\begin{array}{c}\text { Population } \\
\text { controls }\end{array}$ \\
& & &
\end{tabular}

\begin{tabular}{lllll}
\hline $\begin{array}{l}\text { Males } \\
\text { Childhood } \\
\text { eczema }\end{array}$ & & & & \\
$\quad$ Yes & $38.9(20)$ & $12.8(10)$ & $17.2(11)$ & $8.5(6)$ \\
$\quad$ No & $28.1(152)$ & $10.1(76)$ & $10.6(62)$ & $10.4(62)$ \\
$\begin{array}{l}\text { Family } \\
\text { history }\end{array}$ & & & & \\
$\quad$ Yes & $52.9(18)$ & $15.2(8)$ & $11.6(5)$ & $14.3(7)$ \\
$\quad$ No & $27.5(139)$ & $9.5(66)$ & $10.8(59)$ & $9.8(54)$ \\
Females & & & & \\
Childhood & & & & \\
eczema & & & & \\
$\quad$ Yes & $40.1(14)$ & $22.2(13)$ & $28.7(15)$ & $30.6(16)$ \\
$\quad$ No & $28.5(59)$ & $11.6(45)$ & $14.5(45)$ & $12.9(39)$ \\
Family & & & & \\
history & & & & \\
$\quad$ Yes & $30.5(80)$ & $18.8(10)$ & $16.6(7)$ & $45.5(17)$ \\
$\quad$ No & $28.6(57)$ & $12.1(44)$ & $15.9(48)$ & $12.8(35)$ \\
\hline
\end{tabular}

Data are shown as number of new cases 1,000 person-yrs ${ }^{-1}$ according to childhood eczema or a family history of atopic eczema (number of incident cases).

In addition the three comparison groups (bakers in other occupations together with school and population controls) were combined and the relative risks for bakers of developing hay fever or rhinitis during bakery work were calculated and compared with this combined comparison group. The risk for hay fever was $1.9(95 \%$ CI $1.2-2.9)$ for males and 0.86 (95\% CI $0.43-1.7)$ for females. The relative risk for rhinitis in males was 2.8 (95\% CI 2.3-3.4) and for females $2.0(95 \%$ CI 1.6-2.7) compared with the combined control groups.

The multiple logistic regression showed significant associations between prevalence of rhinitis and all variables except for sex and a family history of asthma. The odds ratios and 95\% CI for the "ever bakers" was 2.5 (1.8-3.4) compared with "never bakers" 1.7 (1.4-2.2) compared with school controls and 1.8 (1.5-2.3) compared with population controls. The odds ratio for childhood eczema was $1.6(95 \%$ CI $1.3-2.0)$ and for a family history of hay fever $1.7(1.4-2.2)$

Table 6. - Incidence rates of hay fever and rhinitis when working as a baker, according to time after start of employment

\begin{tabular}{lccc}
\hline & \multicolumn{3}{c}{ Years after start of employment } \\
\cline { 2 - 4 } & $\leq 1$ & $2-5$ & $\geq 6$ \\
\hline Hay fever & & & \\
Males & $10.2(13)$ & $3.0(7)$ & $3.1(10)$ \\
$\quad$ Females & $5.6(5)$ & $2.5(3)$ & $3.7(2)$ \\
Rhinitis & & & \\
$\quad$ Males & $29.5(37)$ & $37.8(81)$ & $22.3(60)$ \\
Females & $35.3(31)$ & $28.9(32)$ & $23.6(11)$ \\
\hline
\end{tabular}

Number of incident cases is given in parentheses.
Table 7. - Incidence rates of hay fever and rhinitis from the age of $18 \mathrm{yrs}$ onwards according to age

\begin{tabular}{|c|c|c|c|c|}
\hline & \multicolumn{2}{|c|}{ Former bakery student } & \multirow[b]{2}{*}{$\begin{array}{l}\text { School } \\
\text { controls }\end{array}$} & \multirow[b]{2}{*}{$\begin{array}{c}\text { Population } \\
\text { controls }\end{array}$} \\
\hline & $\begin{array}{l}\text { When } \\
\text { working } \\
\text { as baker }\end{array}$ & $\begin{array}{l}\text { When in } \\
\text { other } \\
\text { occupation }\end{array}$ & & \\
\hline \multicolumn{5}{|l|}{ Hay fever } \\
\hline \multicolumn{5}{|l|}{ Males } \\
\hline \multicolumn{5}{|l|}{ Age yrs } \\
\hline$\leq 25$ & $5.9(26)$ & $1.2(1)$ & $2.1(2)$ & $6.3(5)$ \\
\hline$\geq 26$ & $1.6(4)$ & $2.9(24)$ & $1.9(11)$ & $1.7(11)$ \\
\hline \multicolumn{5}{|l|}{ Females } \\
\hline \multicolumn{5}{|l|}{ Age yrs } \\
\hline$\leq 25$ & $4.1(9)$ & $6.0(9)$ & $8.1(7)$ & $4.0(3)$ \\
\hline$\geq 26$ & $2.4(1)$ & $2.6(9)$ & $5.0(15)$ & $4.1(12)$ \\
\hline \multicolumn{5}{|l|}{ Rhinitis } \\
\hline \multicolumn{5}{|l|}{ Males } \\
\hline \multicolumn{5}{|l|}{ Age yrs } \\
\hline$\leq 25$ & 35.7 (147) & 18.0 (14) & 11.8 & $16.7(13)$ \\
\hline$\geq 26$ & $16.2(32)$ & $9.3(73)$ & $11.0(62)$ & $9.2(55)$ \\
\hline \multicolumn{5}{|l|}{ Females } \\
\hline \multicolumn{5}{|l|}{ Age yrs } \\
\hline$\leq 25$ & $30.8(65)$ & $17.1(25)$ & $27.9(23)$ & $28.3(20)$ \\
\hline$\geq 26$ & $26.3(9)$ & $10.8(34)$ & $13.0(37)$ & $12.5(36)$ \\
\hline
\end{tabular}

Data are shown as number of new cases 1,000 person-yrs ${ }^{-1}$ according to age (number of incident cases).

\section{Discussion}

This study showed an increased incidence of rhinitis and, for males of hay fever during bakery work. An atopic history further increased these incidences. Bakers changed job because of nasal symptoms more often than control subjects.

Before discussing the significance of these findings, some methodological aspects need to be considered. A selfselection out of bakery school of persons with atopy affecting the nose seems most probable and is supported by lower prevalences of hay fever and rhinitis up to the age of $15 \mathrm{yrs}$ and a lower prevalence of a family history of hay fever among baker students compared to controls (table 1). The differences in incidence of hay fever and rhinitis between bakers and control subjects would, therefore, probably have been larger if there had been no selection bias.

Two kinds of information bias are possible; misclassification by diagnosis and by time of onset of disease. Rhinitis can be classified as "allergic" or "nonallergic". The allergic label is used when a causative allergen can be identified [14]. This approach to classification might lead to problems in epidemiological studies because of the difficulty in identifying allergens using a questionnaire. The question of occurrence of "hay fever" has been used as a substitute for allergic rhinitis. Self-reported hay fever was validated against a Phadiatop screening test [15] and against a skin test with common allergens [16]. The positive predictive values of the question on hay fever in the two studies were 37 and $43 \%$, respectively. This means that about $40 \%$ of the subjects reporting present or past hay fever seem to have a positive allergy test to common allergens.

The validation of questions of self-reported rhinitis is hampered by the lack of agreed definitions of this condition [17]. To the authors' knowledge, there is only one 
reported validation of self-reported rhinitis in general. SiBBALD and RINK [18] compared a mailed questionnaire with in-depth interviews. Assuming the interview as the "gold standard", the agreement was good with a sensitivity of $96 \%$ and a specificity of $91 \%$. The questionnaire asked about sneezing, runny nose and blocked nose. These nasal symptoms were recommended for epidemiological use by the European position paper [14]. The present study followed these recommendations, adding that rhinitic symptoms should occur without having a cold.

There is no obvious reason why rhinitis would be reported falsely more frequently during bakery work. Most people do not regard rhinitis as a serious disease. If former baker students were ascribing rhinitis onset to time as a baker, the incidences during work in other occupations would be lower than in the two other control groups. That was not the case in the present study. Furthermore, there was a satisfactory reliability of the questions on time of onset of hay fever and rhinitis (29 out of 42 subjects reported onset of rhinitis within 2 yrs on the two occasions). Thus, it is unlikely that there was any significant information bias.

Epidemiological knowledge on the occurrence of nasal symptoms in adults is sparse. The authors are not aware of any other study on the incidence of rhinitis in an occupational setting and found only one study on the incidence of hay fever in the general population [19]. The incidence of hay fever in that population sample was about five cases $\cdot 1,000$ person-yrs ${ }^{-1}$, which is in the same range as the present results (table 2).

The increased incidence of hay fever during bakery work among males may be attributed to misclassification between hay fever and rhinitis. A true increase in the incidence of hay fever during bakery work was also possible. Cereals are taxonomically related to common grasses [20] and immunological cross-reactions between flour allergens and grass pollen are possible [21]. The absence of an increased incidence in females could be a parallel to the previous findings of an increased incidence of asthma during bakery work only in males [10].

In general, the incidence rates of hay fever and rhinitis were highest during the first years of bakery work. This may indicate that nasal symptoms are induced quickly in bakers but might also be an effect of higher incidence rates in general in the younger ages (table 7). Since the most common course of events for bakery students is to start bakery work shortly after graduating, exposure is more likely to occur in the younger than in the older groups.

The relative risks for rhinitis when working as a baker are $2-3$. The ratios of the cumulative prevalences for rhinitis between bakers and control subjects are 1.2-1.5, which illustrates the advantage of estimating the incidence rates rather than prevalences. In a study of cross-sectional design, prevalence ratios would probably have been even smaller owing to selection bias: some atopic youths would probably have avoided the bakery trade school and bakers with rhinitis symptoms would have left the occupation. Of the 293 incident cases of hay fever or rhinitis during bakery work, $65(22 \%)$ reported change of work because of nasal symptoms.

A family history of hay fever seems to be a strong predictor for the occurrence of hay fever, both in exposed workers and in control subjects (table 4). The cases are too few to evaluate whether exposure increases the risk of hay fever in persons without a family history of hay fever. A family history of hay fever also seems to be a predictor for the occurrence of rhinitis in exposed people and controls. The excess risk associated with exposure seemed to be higher for people with a family history (i.e. 48.3-16.8 = 31.5 versus $27.7-9.9=17.8 \cdot 1,000$ person- $\mathrm{yrs}^{-1}$ for males using "when in other occupation" as control subjects). This indicates a synergistic effect between a family history of hay fever and exposure to bakery work.

An attempt was also made to calculate the incidence of rhinitis relative to onset of previous hay fever. This proved not to be feasible because most people reporting both rhinitis and hay fever gave the same year of onset for both conditions, resulting in few incident cases of rhinitis after hay fever and unstable incidence estimates. This may be due to misclassification between hay fever and rhinitis, as discussed previously.

The impact of skin atopy on the incidence of rhinitis is more obscure (table 5). In males, both indicators of skin atopy (child hood eczema and a family history of atopic eczema) seemed to be rather weak predictors of rhinitis. In females, a history of own childhood eczema increased the incidence of rhinitis, but the highest incidence rate was found in population controls without a family history of atopic eczema. This may be a random finding.

In conclusion, Swedish bakers, mainly working in the 1970s and 1980s, had an approximately doubled risk of developing rhinitis. Male bakers also had an increased risk for hay fever. There was a synergistic effect of bakery work and atopy such as a family history of hay fever. Bakers also changed their job due to nasal symptoms more often than control subjects.

Acknowledgements. The authors thank D. Klein for computer assistance and A. Fröberg and G. Garsell for word processing.

\section{References}

1. Baagøe KH. Mehlidiosynkrasie als Ursache vasomotorischer Rhinitis und Asthma. Acta Med Scand 1933; 80: 310-322.

2. Järvinen KAJ, Pirilä V, Björksten $F$, Keskinen $H$, Lehtinen M, Stubb S. Unsuitability of bakery work for a person with atopy: a study of 234 bakery workers. Ann Allergy 1979; 42: 192-195.

3. Musk AW, Venables KM, Crook B, et al. Respiratory symptoms, lung function and sensitisation to flour in a British bakery. Br J Ind Med 1989; 46: 636-642.

4. De Zotti R, Larese F, Bovenzi M, Negro C, Molinari S. Allergic airway disease in Italian bakers and pastry makers. Occup Environ Med 1994; 51: 548-552.

5. Cullinan P, Lowson D, Nieuwenhuijsen MJ, et al. Work related symptoms, sensitisation, and estimated exposure in workers not previously exposed to flour. Occup Environ Med 1994; 51: 579-583.

6. Smith TA, Lumley KPS. Work-related asthma in a population exposed to grain, flour and other ingredient dusts. Occup Med 1996; 46: 37-40.

7. Houba R. Occupational Respiratory Allergy in Bakery Workers. Thesis, University of Wageningen, The Netherlands, 1996.

8. Hytönen M, Kanerva L, Malmberg H, Martikainen R, Mutanen P, Toikkanen J. The risk of occupational rhinitis. Int Arch Occup Environ Health 1997; 69: 487-490. 
9. Juniper EF. Measuring health-related quality of life in rhinitis. J Allergy Clin Immunol 1997; 99: 742-749.

10. Brisman SJ, Järvholm BG. Occurrence of self-reported asthma among Swedish bakers. Scand $J$ Work Environ Health 1995; 21: 487-493.

11. Brisman J, Meding B, Järvholm B. Occurrence of selfreported hand eczema among Swedish bakers. Occup Environ Med 1998; 55: 750-754.

12. Cohen J. A coefficient of agreement for nominal scales. Psychol Measure 1960; 20: 37-46.

13. Miettinen OS. Estimability and estimation in case-referent studies. Am J Epidemiol 1976; 103: 226-235.

14. Charpin D, Sibbald B, Weeke E, Wüthrich B. Epidemiologic identification of allergic rhinitis. Allergy 1996; 51: 293-298.

15. Vervloet D, Haddi E, Tafforeau M, Lanteaume A, Kulling G, Charpin D. Reliability of respiratory symptoms to diagnose atopy. Clin Exp Allergy 1991; 21: 733-737.

16. Charpin D, Hughes B, Mallea M, Sutra J-P, Balansard G, Vervloet D. Seasonal allergic symptoms and their relation to pollen exposure in south-east France. Clin Exp Allergy 1993; 23: 435-439.

17. Sibbald B, Strachan DP. Epidemiology of rhinitis. In: Busse WW, Holgate ST, eds. Asthma and Rhinitis. Boston, Blackwell Scientific, 1995; pp. 32-43.

18. Sibbald B, Rink E. Epidemiology of seasonal and perennial rhinitis: clinical presentation and medical history. Thorax 1991; 46: 895-901.

19. Broder I, Higgins MW, Matthews KP, Keller JB. Epidemiology of asthma and allergic rhinitis in a total community, Tecumseh, Michigan. IV. Natural history. $J$ Allergy Clin Immunol 1974; 54: 100-110.

20. Baldo B, Sutton R, Wrigley C. Grass allergens, with particular reference to cereals. Prog Allergy 1982; 30: 266.

21. Sander I, Rauf-Heimsoth $M$, Düser M, Flagge A, Czuppon AB, Baur X. Differentiation between cosensitization and cross-reactivity in wheat flour and grass pollen-sensitized subjects. Int Arch Allergy Immunol 1997; 112: 378-385. 